This is the author's prepublication manuscript of the work. It is posted here by permission from the American Chemical Society for personal use, not for commercial distribution.

The definitive version was published in Environmental Science \& Technology, 2012, 46(6):

3135-3140, doi 10.1021/es204375p (http://dx.doi.org/10.1021/es204375p)

\title{
Aerosol-Mediated Transport and Deposition of Brominated Diphenyl Ethers to Antarctica
}

\author{
Rebecca M. Dickhut ${ }^{\dagger}$, Alessandra Cincinelli ${ }^{\ddagger}$, Michele Cochran ${ }^{\dagger}$ and Henrik Kylin*®\$ \\ ${ }^{\dagger}$ Virginia Institute of Marine Science, College of William \& Mary, P.O. Box 1346, Gloucester \\ Point, VA 23062 \\ ${ }^{\ddagger}$ Dipartimento di Chimica, Università degli Studi di Firenze, Via della Lastruccia, 3, 50019 \\ Sesto Fiorentino (Florence- Italy) \\ "Department of Water and Environmental Studies, Linköping University, SE-581 83 \\ Linköping, Sweden \\ ${ }^{\S}$ Norwegian Institute for Air Research, Fram Centre, NO-9296 Tromsø, Norway
}

Received by the journal 7 December 2011

Revised 14 February 2012

Accepted (web publications date) 27 February 2012

Corresponding Author

*Phone: +46 13282278; fax: +46 13133630, e-mail: henrik.kylin@liu.se 


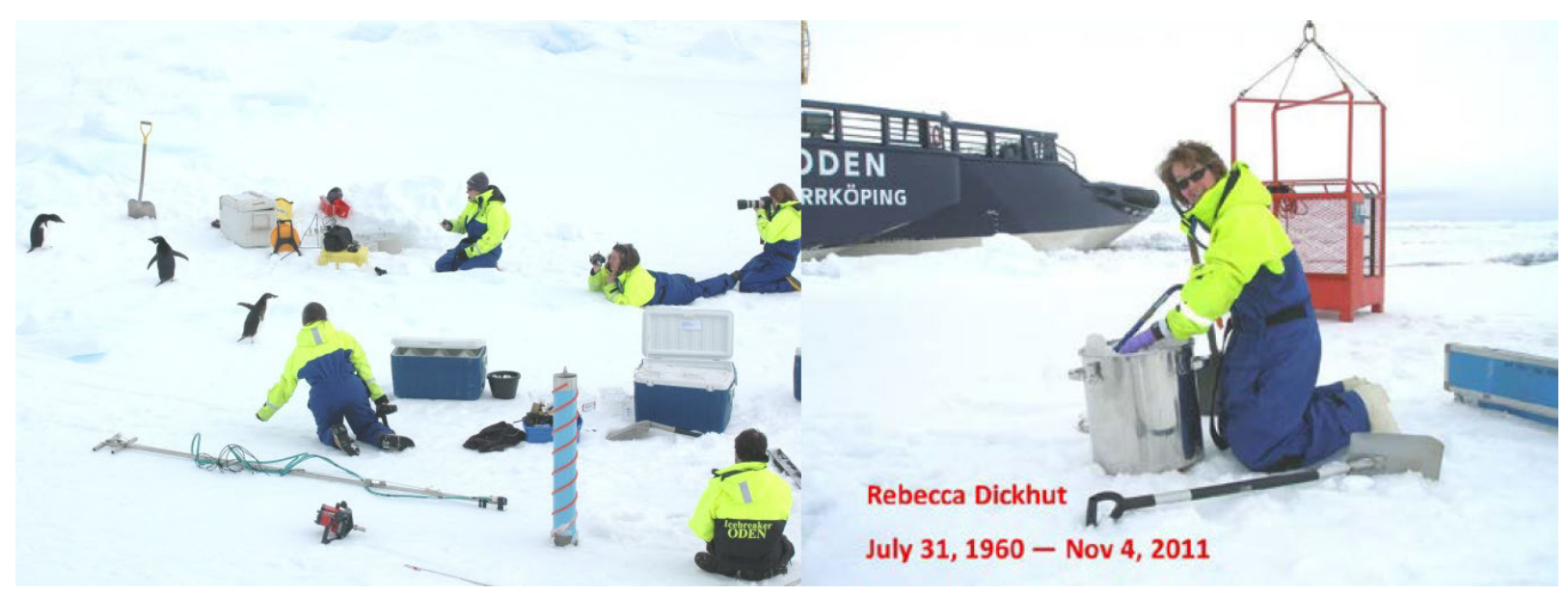

ABSTRACT: Brominated diphenyl ethers (BDEs -47, -99, -100, and -209) were measured in air, snow and sea ice throughout western Antarctica between 2001 and 2007. BDEs in Antarctic air were predominantly associated with aerosols and were low compared to remote regions of the northern hemisphere, except in Marguerite Bay following the fire at Rothera research station in Sept. 2001, indicating that this event was a local source of BDE209 to the Antarctic environment. Aerosol BDE47/100 reflects a mixture of commercial pentaBDE products; however, BDE99/100 is suggestive of photodegradation of BDE99 during long range atmospheric transport (LRAT) in the austral summer. BDEs in snow were lower than predicted based on snow scavenging of aerosols indicating that atmospheric deposition events may be episodic. BDE47, -99, and -100 significantly declined in Antarctic sea ice between 2001 and 2007; however, BDE209 did not decline in Antarctic sea ice over the same time period. Significant losses of BDE99 and -100 from sea ice were recorded over a 19 day period in spring 2001 demonstrating that seasonal ice processes result in the preferential loss of some BDEs. BDE47/100 and BDE99/100 in sea ice samples reflect commercial pentaBDE products, suggesting that photodegradation of BDE99 is minimal during LRAT in the austral winter.

\section{INTRODUCTION}

Long-range atmospheric transport (LRAT) is an important process leading to widespread distribution of pollutants in remote polar regions and metrics of the LRAT potential of pollutants facilitate the development and implementation international treaties to restrict or ban the use of chemicals that may threaten wildlife and humans in remote regions. ${ }^{1}$ Numerous studies on the global distribution of persistent organic pollutants ${ }^{2-8}$ support the mechanistic understanding developed by Wania and Mackay ${ }^{9,10}$ of the movement of relatively volatile chemicals throughout the global environment along with cold trapping of more volatile compounds at high latitudes. However, more recently, several studies have pointed out the potential importance of aerosol-mediated LRAT for compounds such as brominated diphenyl ethers (BDEs), in particular, decabromodiphenyl ether (BDE209). ${ }^{11-14}$ These studies have highlighted the need for improved understanding of the fate and transport of aerosolassociated organic contaminants in the global environment. ${ }^{1}$ 
In 2001 we found BDEs associated with ice algae, phytoplankton, and krill (Euphausia superba) along the western Antarctic Peninsula, ${ }^{15}$ and BDEs have also been found in Antarctic fish and penguins, ${ }^{16,17}$ moss and lichens, ${ }^{18}$ and in sediments and benthic organisms in the vicinity of McMurdo research station in Antarctica. ${ }^{19}$ This latter paper indicated that local inputs from research activities may be an important source of BDEs to the Antarctic marine environment. In contrast, Yogui and Sericano found no difference in BDE concentrations in lichens and moss close to and distant from research facilities and suggested LRAT as the source of BDEs to King George Island, Antarctica. ${ }^{18}$ Given the absence of human population in remote regions of Antarctica, the presence of BDEs in these areas would likewise be indicative of LRAT. Here we present data on the widespread distribution of BDEs in the Antarctic cryosphere and evaluate local versus long-range atmospheric sources of BDEs in Antarctica with special emphasis on the mechanism of LRAT of BDEs in the southern hemisphere.

\section{EXPERIMENTAL SECTION}

Sampling Sites. High volume air samples were collected in 2001 and 2002 along the western Antarctic Peninsula, and at a coastal site off of Northern Victoria Land south of the Italian Research base near Terra Nova Bay, Antarctica in 2003 to 2005 (Figure 1). ${ }^{20,21}$ Snow was collected in 2002 in the vicinity of Palmer Station as described elsewhere, ${ }^{15,20}$ and at one site during the expedition of the Swedish Icebreaker Oden in the Southern Ocean (OSO2007). Sea ice was collected in 2001 in Marguerite Bay, ${ }^{15}$ and again in 2007 at various sites in the Amundsen and Ross Seas during OSO2007 (Figure 1).

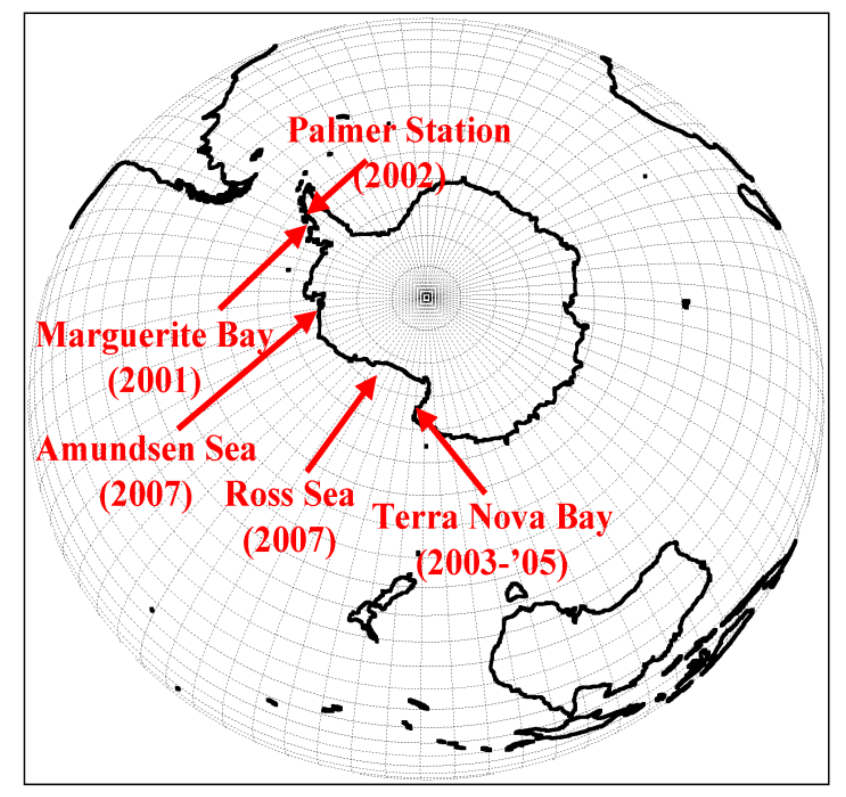

Figure 1. Air, snow, and sea ice sampling locations.

Snow and sea ice were collected as described elsewhere, ${ }^{15}$ and sample meltwater volumes ranged from 40.5 to $147 \mathrm{~L}$ (Tables S2 and S3). Sample and field blank filter composites were Soxhlet extracted for $24 \mathrm{~h}$ each with acetone and dichloromethane after the addition of PCB204 as a surrogate standard, processed as described elsewhere, ${ }^{15}$ and then analyzed for 
BDEs by GC/NCI-MS as described above. Recoveries of the surrogate standard from the snow/ice filter composites averaged $103 \pm 26 \%$.

\section{RESULTS AND DISCUSSION}

Aerosol BDEs. In samples from Palmer Station the BDE contents of both filters and PUF plugs were analyzed, but for most samples the amount found in the PUF plugs was below the method detection limit. The only BDE to be detected in the PUF plugs was BDE47 and only in approximately a third of the samples. Thus, BDEs in Antarctic air were predominantly associated with aerosol particles and averaged ( \pm standard deviation): $0.430( \pm 0.255)$, 0.260( \pm 0.141$), 0.110( \pm 0.113)$, and 103( \pm 54.2$) \mathrm{pg} / \mathrm{m}^{3}$ for BDE47, $-99,-100$, and -209 , respectively, in Marguerite Bay in $2001(\mathrm{n}=2)$; 0.305( \pm 0.078$), 0.285( \pm 0.120)$, $0.060( \pm 0.028)$, and $0.765( \pm 0.233) \mathrm{pg} / \mathrm{m}^{3}$ for BDE47, $-99,-100$, and -209 , respectively, at Palmer Station in $2002(\mathrm{n}=2)$; and 0.218( \pm 0.046$), 0.155( \pm 0.031), 0.060( \pm 0.016)$, and $0.355( \pm 0.324) \mathrm{pg} / \mathrm{m}^{3}$ for BDE47, $-99,-100$, and -209 , respectively, at Terra Nova Bay from $2003-' 05(n=4)$. The concentrations of the main constituents of pentaBDE formulations were similar to those measured by Xie et al. ${ }^{22}$ in the Southern Ocean $\left(67,354^{\circ} \mathrm{S}, 2,064^{\circ} \mathrm{W}\right)$, where BDE47, -99 and -100 (particulate phase) were $0.33,0.10$ and $0.02 \mathrm{pg} / \mathrm{m}^{3}$, respectively. The measured aerosol-associated BDE levels were 4- to 33-times lower than aerosol-associated BDE concentrations measured in the Arctic in 2003 (Figure 2), with the exception of BDE209 in the vicinity of Marguerite Bay, Antarctica in Sept.-Oct. 2001, which was 10-times higher than concentrations measured in East Asia during 2003. ${ }^{23}$ BDE209 is the main component ( $\geq 97 \%$ ) of the decaBDE commercial product, which is used primarily as a flame retardant in plastic and polymers used in electrical and electronic equipment, and is also used in textiles. ${ }^{24}$, 25 The source of the elevated airborne particulate BDE209 to the Marguerite Bay region in Sept.-Oct. 2001 may have been the fire that consumed a laboratory at nearby Rothera Research Station $\left(67^{\circ} 34^{\prime} \mathrm{S}, 68^{\circ} 08^{\prime} \mathrm{W}\right)$ on Sept. $28,2001^{26}$

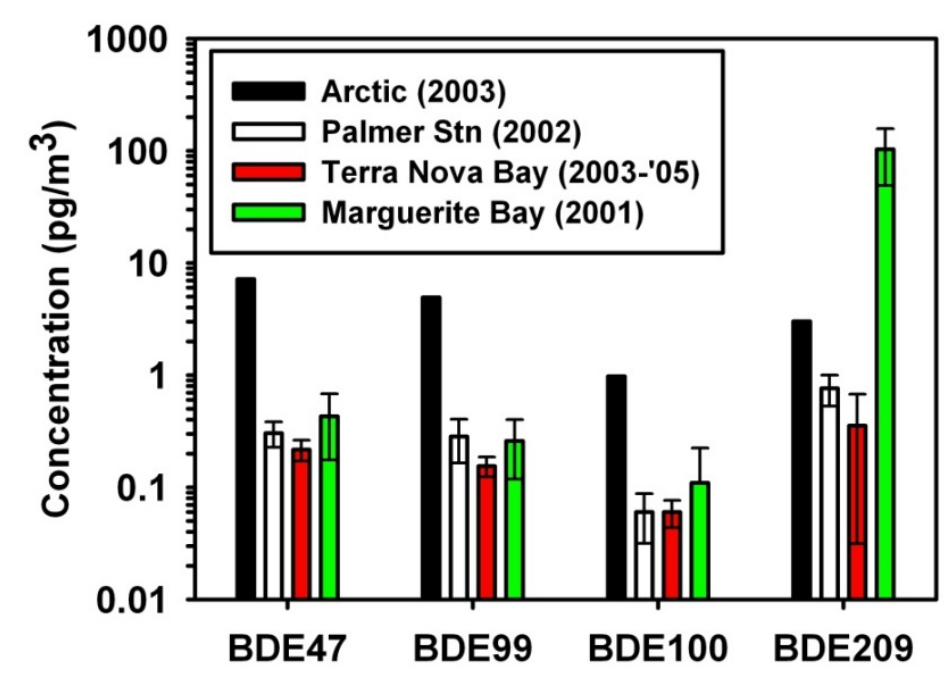

Figure 2. Aerosol-associated BDE concentrations in Antarctica (Palmer Station, Terra Nova Bay, and Marguerite Bay) compared to levels measured in the Arctic during the same time period. $^{23}$ 
The local source of BDE 209 was reflected in the lack of a significant correlation ( $p \geq 0.14)$ between it and the other BDE congeners associated with aerosol particles. In contrast, BDEs $-47,-99$, and -100 , the primary components of the commercial pentaBDE formulations ${ }^{27}$ were significantly correlated (Figure 3) and provide insights into the sources and fate of BDEs during atmospheric transport to Antarctica. The average ratio of BDE47/100 ( \pm standard error) in the Antarctic aerosol samples (3.6( \pm 0.3$)$; Figure 3$)$ falls in between ratios measured in the commercial pentaBDE formulations (DE-71 = 2.92; Bromkal 70-5DE $=5.47$ ), ${ }^{27}$ whereas the average ratio of BDE99/100 (2.45( \pm 0.41$)$; Figure 3$)$ falls below ratios measured in the commercial pentaBDE formulations (DE-71 $=3.71$; Bromkal 70-5DE $=5.37$ ). ${ }^{27}$ The photodegradation half-lives for the pentaBDE components decrease as follows: BDE100 > BDE47 > BDE99 indicating that BDE99 is the most photolabile of these three BDE congeners. ${ }^{28,29}$ Therefore, the low level of BDE99/100 associated with the aerosol particles likely indicates that BDE99 is photodegraded during LRAT from source regions during the austral spring and summer when the air samples were collected. In Alert, Canada, the average ratio of BDE 99/100 was 5.4( \pm 1.4 ) and 47/99 1.1( \pm 0.26 ) (giving a ratio of 47/100 of $~ 5.9) .{ }^{14}$ The lower ratios in the Antarctic compared to the Arctic may reflect that although Alert is located at a higher latitude $\left(82^{\circ} \mathrm{N}\right)$ it is closer to a large land mass with emission sources.

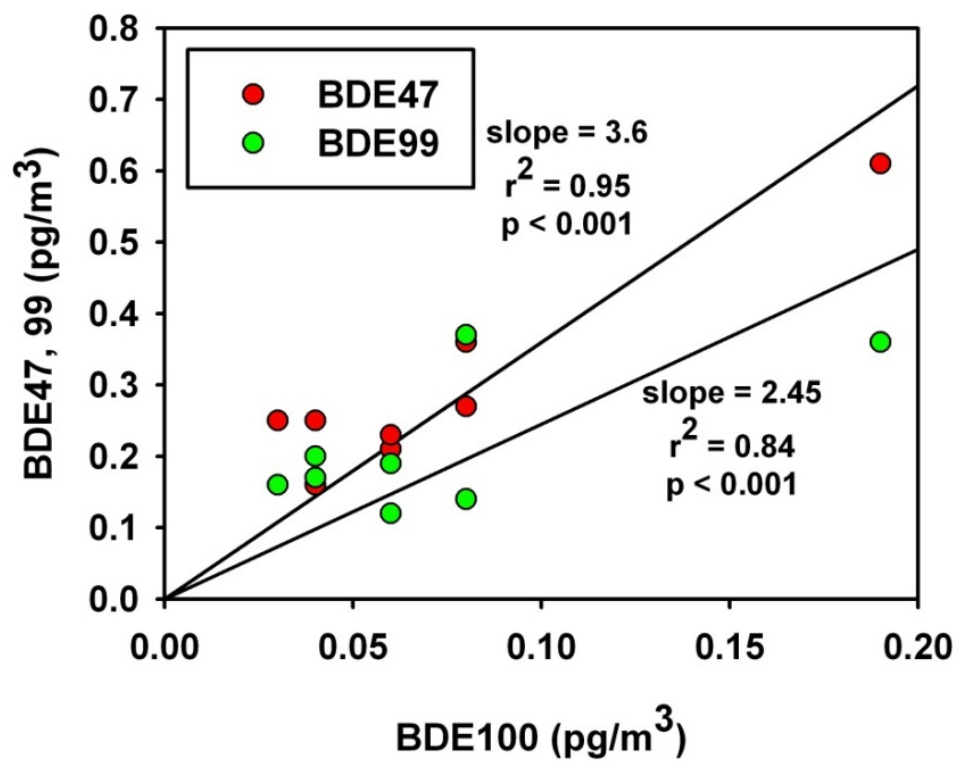

Figure 3. BDE47/100 and BDE99/100 associated with aerosol particles collected in Antarctica during the austral spring and summer.

Of the 4 BDE congeners included in this study, only BDE47 was measured above the MDL in the gas phase and only in $\sim 1 / 3$ of the samples collected at Palmer Station during summer 2002 that had previously been analyzed for organochlorine pesticides. ${ }^{20}$ Because of the low detection frequency of BDE47 and lack of gas-phase data on the three other analytes calculations of gas-aerosol partitioning based on our data is not meaningful, but calculations based on partitioning characteristics measured for $\mathrm{BDEs}^{30}$ corrected for aerosol characteristics representative of Antarctica ${ }^{31}$ are possible. The average air temperature at Palmer Station was $2.1{ }^{\circ} \mathrm{C}$ during summer (Jan.-Feb.) 2002. At this air temperature, 56\% of BDE47 is estimated 
to be in the gas phase in Antarctic air, compared to $\leq 20 \%$ of BDE99 and -100 . However, owing to a strong dependence of partitioning on temperature, at average winter air temperatures $\left(\sim-10^{\circ} \mathrm{C}\right) 85 \%$ of BDE47 and $>96 \%$ of BDE99 and -100 are predicted to be aerosol associated. Consequently, during the polar winter, BDEs will be predominantly associated with aerosol particles in Antarctic air, and aerosol scavenging and deposition will control the accumulation of BDEs in the Antarctic cryosphere.

Snow Scavenging. BDEs were analyzed in a limited number of snow samples $(n=4$ from Palmer Station, 2002; $n=1$ from the Ross Sea in 2007) and were below the MDL in several cases (Table S2). The average measured snow concentrations were compared to particlebound BDE concentrations in snow predicted with two different methods $\left(C_{p, \text { snow }}, \mathrm{pg} / \mathrm{L}\right.$; Figure 4) using the equation:

$$
C_{p, \text { snow }}=W_{p} \cdot C_{p, \text { air }} \cdot 0.001
$$

where $C_{p, a i r}\left(\mathrm{pg} / \mathrm{m}^{3}\right)$ is the average measured aerosol particle concentration (excluding BDE209 measurements from Marguerite Bay) and $W_{p}$ is the snow scavenging coefficient. However, $W_{p}$ estimates may vary over at least an order of magnitude. Franz and Eisenreich, ${ }^{32}$ e.g., measuring snow scavenging of PCB found $W_{p}$ spanning about an order of magnitude with an average of $5.4 \times 10^{5}\left(\left[\mathrm{pg} / \mathrm{m}^{3}\right] /\left[\mathrm{pg} / \mathrm{m}^{3}\right]\right.$, i.e., dimensionless $)$. Clarke, ${ }^{33}$ found a $W_{p}$ for soot ranging between $5 \times 10^{4}$ and $2 \times 10^{5}$ in northern Sweden, and an average soot $W_{p}$ of 1.5 $\times 10^{5}$ was measured in Antarctica. ${ }^{34}$ Comparing our data with values predicted by the average soot $W_{p}$ for Antarctica ${ }^{34}$ indicates that snow scavenging can account for the BDEs found in the cryosphere throughout Antarctica (Figure 4). On the other hand, using the average $W_{p}$ for $\mathrm{PCB}^{32}$ for the predictions (Figure 4), indicates that show scavenging of BDEs in Antarctic either may be significantly less efficient than snow scavenging of PCB in northern temperate regions (paired t-test, $\mathrm{p}=0.03$ ), or that the snow events are much longer. Most aerosols are rapidly scavenged during snow events, why prolonged snow fall will lead to an apparent dilution of the contaminant concentrations in the snow.

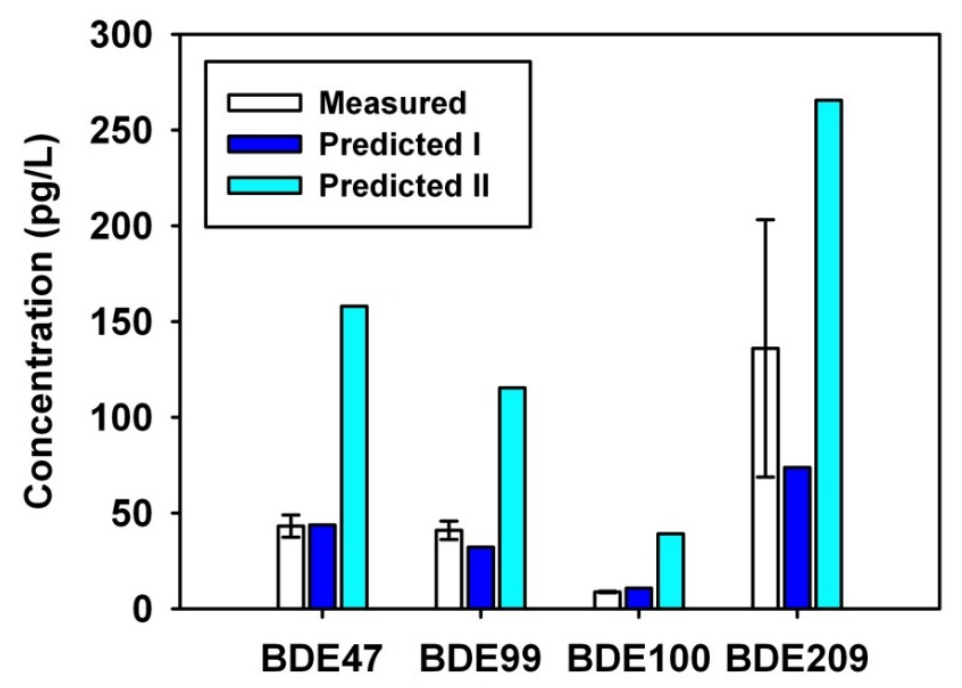

Figure 4. Measured versus two predicted concentrations of particle-bound BDEs in Antarctic snow. 'Predicted I' is based on measurements of the snow scavenging of soot in the Antarctic, ${ }^{34}$ and 'Predicted II' on the snow scavenging of PCB. ${ }^{32}$ 
Sea Ice BDEs. BDEs in Antarctic sea ice averaged ( \pm standard deviation): $188( \pm 38)$, 204( \pm 91$)$, 38.5( \pm 13.7$)$, and 585( \pm 404$) \mathrm{pg} / \mathrm{L}$ for BDE47, $-99,-100$, and -209 , respectively, in Marguerite Bay in $2001(\mathrm{n}=4)$, and 32.2( \pm 14.9$), 30.0( \pm 9.5), 5.5( \pm 3.0)$, and 2920 $( \pm 3240)$ pg/L for BDE47, -99, -100, and -209, respectively, in the Amundsen and Ross Seas in 2007 (n $=7$ ) (Figure 5). Levels of BDE47, -99, and -100 in sea ice were significantly lower (t-tests, $\mathrm{p}$ $<0.0006$ ) in 2007 compared to 2001, whereas there was no significant difference (t-test, $\mathrm{p}=$ 0.19) in BDE209 in sea ice between 2001 and 2007.

The sea ice sampling locations differed spatially being restricted to Marguerite Bay $\left(\sim 68^{\circ} \mathrm{S}\right.$; Table S2) in 2001 and occurring at higher latitudes (71으 - 78 S; Table S3) in 2007, farther away from potential BDE sources given that there are no permanent research bases in the Amundsen or western Ross Seas. However, given the significantly lower concentrations of BDE47, -99, and -100, but not of BDE209, it is unlikely that spatial differences account for the decline of the BDE47, -99, and-100, since the greater distance from potential sources should have also resulted in significantly lower levels of BDE209 in the sea ice in 2007 compared to 2001. A possible explanation for the concentration decline of the lesser brominated BDEs, but not BDE209, in sea ice between 2001 and 2007 is the decline in global use of the commercial pentaBDE formulations. The pentaBDE formulations were banned by the European Union in $2004^{35}$ and the manufacture was voluntarily discontinued in the U.S. shortly thereafter. ${ }^{36}$ However, in spite of the decreased use of pentaBDE formulations the air concentrations in the Arctic continued to increase through 2005 . $^{14,37}$

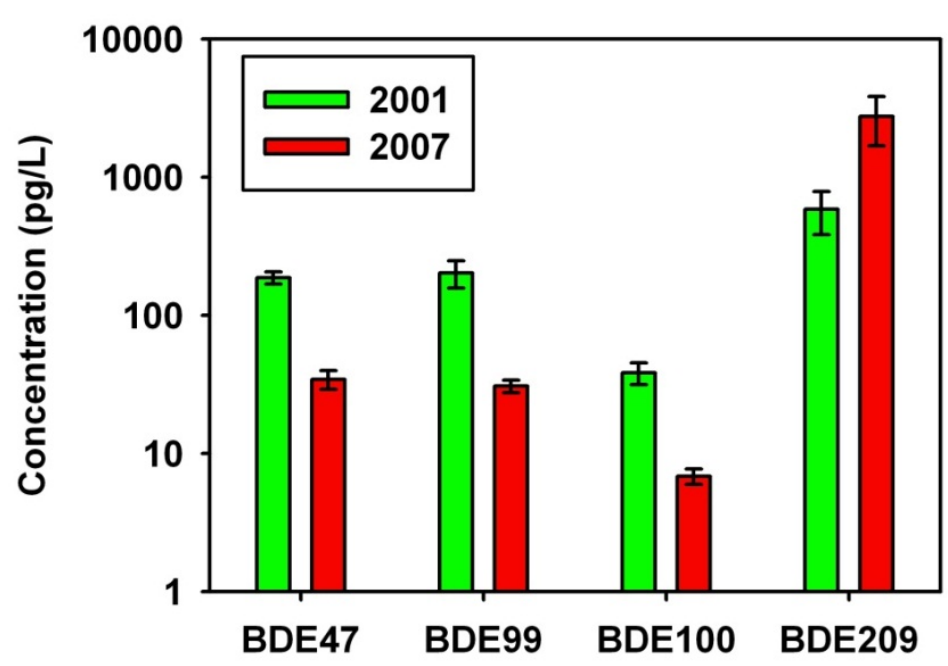

Figure 5. Particle-associated BDE concentrations in Antarctic sea ice (mean \pm standard error).

An alternative explanation for the concentration decline of BDE47, -99, and-100 in the Antarctic sea ice is preferential degradation or leaching from particles during sea ice formation and percolation of brine. BDEs associated with airborne particulates become incorporated into sea ice by snow scavenging and the formation of snow ice, ice formed when snow is infiltrated by water and refreezes. ${ }^{38}$ In late winter (July-Aug.) 2001, 15\% of the sea ice in Marguerite Bay was composed of snow ice and 95\% of the sea ice was above the percolation threshold indicating that it was permeable to brine transport. ${ }^{38}$ The continued 
formation of snow ice during spring and summer due to the infiltration of deep snow with seawater and refreezing likely adds aerosol BDEs to the sea ice; however, repeated percolation of sea ice with brine may simultaneously leach the more soluble BDEs.

Sea ice sampling for BDEs in Marguerite Bay began in late Sept. 2001 and was conducted over a period of 19 days during which time BDE99 and -100 significantly declined, and BDE209 significantly increased (Figure 6). Sea ice was sampled by first removing overlying snow and then collecting and compositing 1-m ice cores. Moreover, given that BDE209 concentrations in Marguerite Bay sea ice were not significantly different from those measured in sea ice in the Amundsen and Ross Seas (Figure 5) the observed trend in BDE209 in Marguerite Bay sea ice is likely not due to increased inputs following the fire at Rothera. Rather, the increase in BDE209 in Marguerite Bay sea ice throughout the sampling period likely illustrates the continued incorporation of aerosols into sea ice throughout spring due to continued snow ice formation.

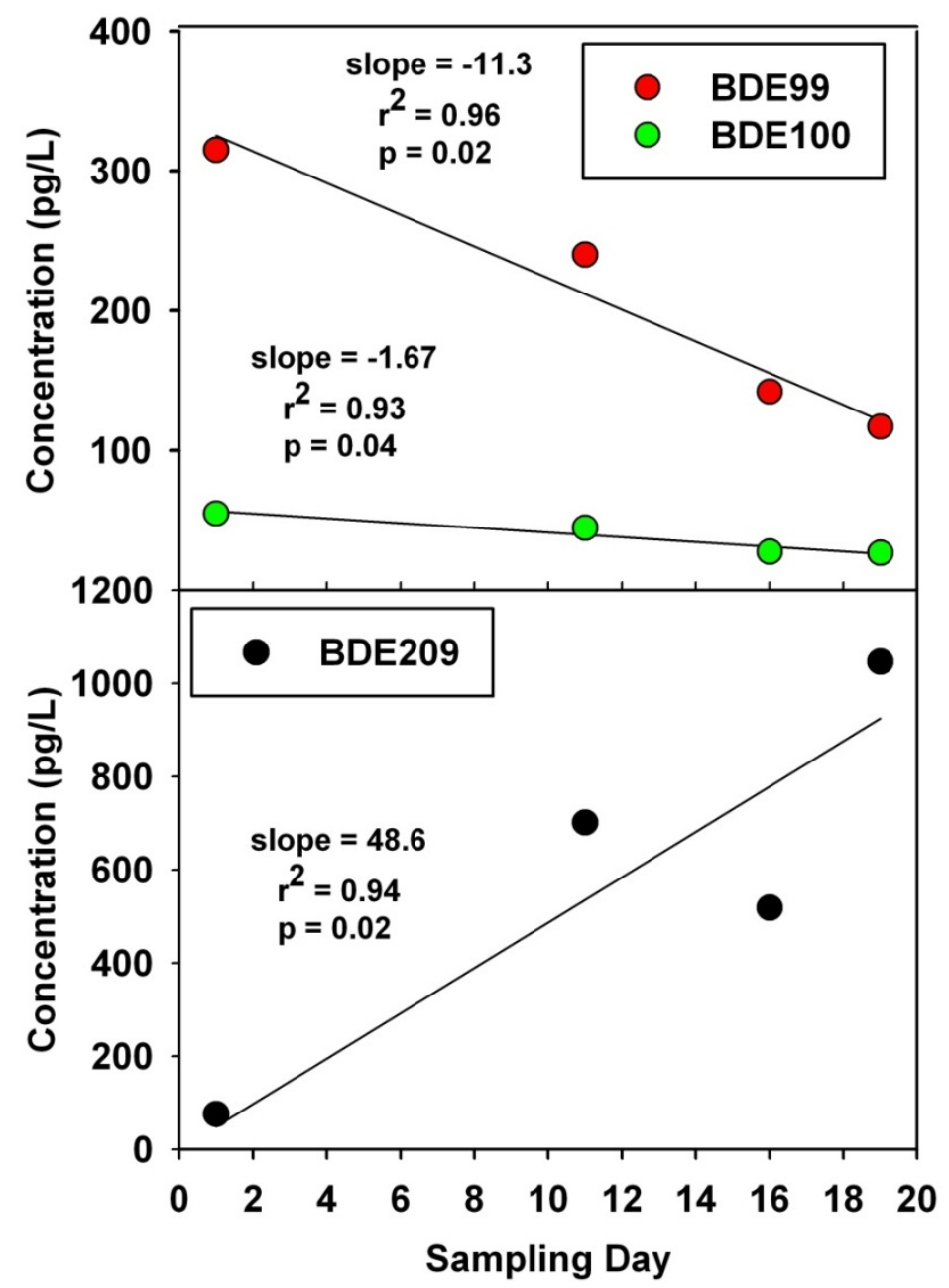

Figure 6. Change in BDE composition in sea ice in Marguerite Bay, Antarctica during spring 2001.

In contrast to BDE209, the significant declines in BDE99 and -100 in Marguerite Bay sea ice (Figure 6) suggest that removal processes dominated for these congeners during the spring 
sampling period. BDE100 is the most soluble of the BDE congeners studied; ${ }^{39}$ therefore, loss of this congener from sea ice may have been due to leaching in excess of BDE100 added by new snow ice formation. Although it is less soluble, ${ }^{39}$ BDE99 declined more rapidly in sea ice compared to BDE100 (Figure 6). The more rapid loss of BDE99 suggests an additional removal process was operational, which may have been photodegradation in the snow pack such that the input of BDE99 via snow ice formation was low compared to the other BDEs. Finally, no significant change ( $p=0.8$ ) in BDE47 concentrations was found in the Marguerite Bay sea ice samples, indicating that over the 19 day sampling period BDE47 was at steady state with the rate of input from the formation of new snow ice matching rate of loss of BDE47 from sea ice. As most of the PUF plug samples did not yield any detectable concentrations of the BDEs, further explanation of the observed differences between the tetrabrominated BDE47 and the pentabrominated BDEs -99 and -100 will have to wait until relevant data become available.

The short-term temporal data for BDEs in sea ice in Marguerite Bay offers a potential explanation for the lower levels of BDE47, -99, and -100 observed in sea ice in 2007 versus 2001. Sea ice sampling in 2007 was conducted later in the year (mid-summer compared to spring in 2001). Consequently, the lower levels of BDE47, -99, and -100 in the 2007 sea ice samples compared to the 2001 samples may have been due to the increased time throughout the spring and summer for leaching and degradation of the lower brominated BDEs from the sea ice. Thus, the apparent decline of the pentaBDE congeners in Antarctic sea ice between 2001 and 2007 (Figure 5) may be due to seasonal processes occurring within sea ice rather than reflective of an overall reduction in the global sources of BDEs.

Finally, although BDE99 declined more rapidly in Marguerite Bay sea ice compared to BDE100, the ratio of BDE99/100 remained more or less constant (i.e., the relative degradation rates were similar), and similar to known ratios for the commercial pentaBDE formulations ${ }^{27}$ suggesting that photodegradation of BDE99 was minimal during LRAT and deposition during the Antarctic winter when the sea ice and overlying snow accumulate, and when sunlight is at a minimum. Likewise, BDEs $-47,-99$, and -100 were significantly correlated in sea ice collected in 2007 (Figure 7). Again, both BDE47/100 and BDE99/100 fall in between values measured for the commercial pentaBDE formulations ${ }^{27}$ suggesting that unlike aerosol particles collected in summer, there is little if any photodegradation of BDEs during poleward atmospheric transport and deposition in the austral winter.

LRAT of BDEs to Antarctica. The widespread distribution of BDEs in the cryosphere of remote Antarctic regions can only be explained by LRAT, and is further supported by the measurement of these compounds in Antarctic air. Moreover, the emerging picture from these data is that BDEs are atmospherically transported to Antarctica along with aerosols with little fractionation or degradation, particularly during winter. The observation that BDE47, -99, and -100 in Antarctic mosses and lichens reflect commercial pentaBDE formulations, ${ }^{18}$ supports this picture. However, this scenario differs from expectations based on the theory of global distillation, whereby more volatile components (e.g., BDE47) are predicted to be transported greater distances than less volatile components (e.g., BDE99 and -100) resulting in fractionation of the original source mixture, which becomes enriched in the more volatile 
components in condensed phases of remote polar regions. ${ }^{9,10}$ This lack of conformation with cold condensation theory may result from a combination of the climate and geography of the southern hemisphere, and the physical-chemical properties of BDEs.

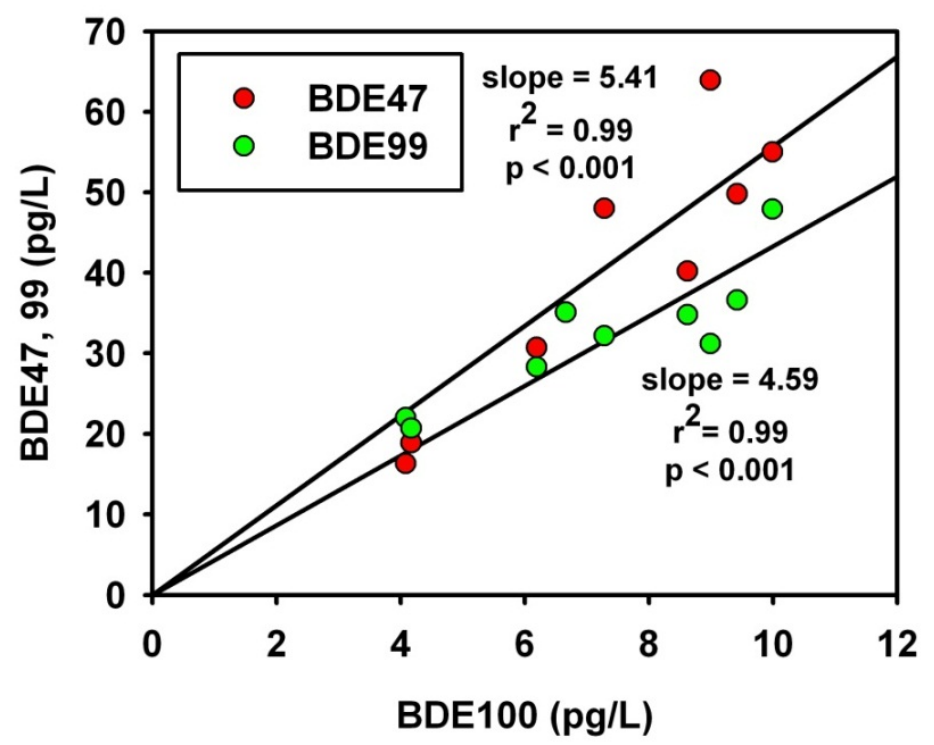

Figure 7. BDE47/100 and BDE99/100 associated with sea ice particulate matter collected in Antarctica in 2007.

In the southern hemisphere, the dominant air mass movements include transport toward the equator at the Earth's surface from $30^{\circ} \mathrm{S}$ constituting the southeast trade winds, and poleward transport of air along with strong westerlies between $30^{\circ} \mathrm{S}$ and $60^{\circ} \mathrm{S} .{ }^{40} \mathrm{In}$ winter, the mean air temperature ranges from $15^{\circ} \mathrm{C}$ at $30^{\circ} \mathrm{S}$ and rapidly declines to $<0^{\circ} \mathrm{C}$ at $60^{\circ} \mathrm{S}$ (Figure S1). At these air temperatures, $99.9 \%$ of BDE209 is predicted to be associated with aerosol particles in the atmosphere. ${ }^{12}$ Therefore, BDE209 must originate and undergo LRAT to Antarctica entirely associated with aerosol particles in the austral winter. The range of latitudes from which aerosol BDEs deposited to Antarctica originate can be further narrowed using an upper estimate of the residence time for aerosols in the troposphere of 12 days. ${ }^{41}$ Twelve day air mass back trajectories from the ice sampling locations during winter (Figure S2) ${ }^{42,43}$ demonstrate that the air parcels that transport BDEs to Antarctica in winter remain south of $40^{\circ} \mathrm{S}$ where the upper limit for the mean winter air temperature is $10.5^{\circ} \mathrm{C}$. At this air temperature, $60 \%$ of BDE47 and $88-89 \%$ of BDE99 and -100 are predicted to be associated with aerosol particles. ${ }^{30}$ Consequently, the major components of the commercial pentaBDE formulation will also undergo LRAT to Antarctica in association with aerosol particles in winter.

ACKNOWLEDGMENTS The co-authors remember the late Dr. Rebecca Dickhut with warmth and gratitude, and thank Dr. Andrew Wozniak for help to complete the manuscript at her demise. An anonymous reviewer gave valuable input to the manuscript, and Agneta Fransson provided the right photo of the TOC-art. We thank the captains and crews of the $R / V$ Nathaniel B. Palmer and the Icebreaker Oden, and the staff at Palmer Research Station and Mario Zucchelli Station for their help with this project. The authors gratefully acknowledge the NOAA Air Resources Laboratory for the provision of the HYSPLIT transport and dispersion model and/or READY website (http://www.arl.noaa.gov/ready.php) used in this publication. The US Antarctic Program, the Italian National Project of Antarctic Research and the Swedish Polar Research Secretariat provided 
logistic support. This project was funded by the National Science Foundation, Office of Polar Programs, Award Nos. 0087872 and 0741379, the Swedish Research Council and the Italian Antarctic Research Program. VIMS contribution no. 3219.

SUPPORTING INFORMATION Tables S1-S3 with data on concentration of particle bound BDEs in air and Figures S1 and S2 of winter air temperature and air mass back trajectories. This material is available free of charge via the Internet at http://pubs.acs.org.

\section{REFERENCES}

(1) Scheringer, M. Long-range transport of organic chemicals in the environment. Environ. Toxicol. Chem. 2009, 28 (4), 677-690.

(2) Simonich, S.L.; Hites, R.A. Global distribution of persistent organochlorine compounds. Science 1995, 269 (5232), 1851-1854.

(3) Bacci, E.; Calamari, D.; Gaggi, C.; Fanelli, R.; Focardi, S.; Morosini, M. Chlorinated hydrocarbons in lichen and moss samples from the Antarctic Peninsula. Chemosphere 198615 (6), 747-754.

(4) Calamari, D.; Bacci, E.; Focardi, S.; Gaggi, C.; Morosini, M.; Vighi, M. Role of plant biomass in the global environmental partitioning of chlorinated hydrocarbons. Environ. Sci. Technol. 1991, 25 (8), 1489-1495.

(5) Weber, K.; Goerke, H. Organochlorine compounds in fish off the Antarctic Peninsula. Chemosphere 1996, 33 (3), 377-392.

(6) Agrell, C.; Okla, L.; Larsson, P.; Backe, D.; Wania, F. Evidence of latitudinal fractionation of polychlorinated biphenyl congeners along the Baltic Sea region. Environ. Sci. Technol. 1999, 33 (8), 1149-1156.

(7) Kalantzi, O.I.; Alcock, R.E.; Johnston, P.A.; Santillo, D.; Stringer, R.L.; Thomas, G.O.; Jones, K.C. The global distribution of PCBs and organochlorine pesticides in butter. Environ. Sci. Technol. 2001, 35 (6), 1013-1018.

(8) Sobek, A.; Gustafsson, Ö. Latitudinal fractionation of polychlorinated biphenyls in surface seawater along a $62^{\circ} \mathrm{N}-89^{\circ} \mathrm{N}$ transect from the southern Norwegian Sea to the North Pole area. Environ. Sci. Technol. 2004, 38 (10), 2746-2751.

(9) Wania, F.; Mackay, D. Global Fractionation and Cold Condensation of Low Volatility Organochlorine Compounds in Polar Regions. Ambio 1993, 22 (1), 10-18.

(10) Wania, F.; Mackay, D. Tracking the distribution of persistent organic pollutants. Environ. Sci. Technol. 1996, 30 (9), 390A-396A.

(11) Hoh, E.; Hites, R.A. Brominated flame retardants in the atmosphere of the east-central United States. Environ. Sci. Technol. 2005, 39 (20), 7794-7802.

(12) Breivik, K.; Wania, F.; Muir, D.C.G.; Alaee, M.; Backus, S.; Pacepavicius, G. Empirical and modeling evidence of the long-range atmospheric transport of decabromodiphenyl ether. Environ. Sci. Technol. 2006, 40 (15), 4612-4618.

(13) Gouin T.; Thomas G.O.; Chaemfa C.; Harner, T.; Mackay, D.; Jones, K.C. Concentrations of decabromodiphenyl ether in air from Southern Ontario: Implications for particle-bound transport. Chemosphere 2006, 64 (2), 256-261.

(14) Su, Y.; Hung, H.; Sverko, E.; Fellin, P.; Li, H. Multi-year measurements of polybrominated diphenyl ethers (PBDEs) in the Arctic atmosphere. Atmos. Environ. 2007, 41 (38), 8725-8735.

(15) Chiuchiolo, A.L.; Dickhut, R.M.; Cochran, M.A.; Ducklow, H.W. Persistent organic pollutants at the base of the Antarctic marine food web. Environ. Sci. Technol. 2004, 38 (13), 3551-3557. 
(16) Corsolini, S.; Covaci, A.; Ademollo, N.; Focardi, S.; Schepens, P. Occurrence of organochlorine pesticides (OCPs) and their enantiomeric signatures, and concentrations of polybrominated diphenyl ethers (PBDEs) in the Adélie penguin food web, Antarctica. Environ. Pollut. 2006, 140 (2), 371-382.

(17) Corsolini, S.; Borghesi, N.; Schiamone, A.; Focardi, S. Polybrominated diphenyl ethers, polychlorinated dibenzo-dioxins, -furans, and -biphenyls in three species of Antarctic penguins. Environ. Sci. Pollut. Res. 2007, 14 (6), 421-429.

(18) Yogui, G.T.; Sericano, J.L. Polybrominated diphenyl ether flame retardants in lichens and mosses from King George Island, maritime Antarctica. Chemosphere 2008, 73 (10),1589-1593.

(19) Hale, R.C.; Kim, S.L.; Harvey, E.; La Guardia, M.J.; Mainor, T.M.; Bush, E.O.; Jacobs, E.M. Antarctic research bases: Local sources of polybrominated diphenyl ether (PBDE) flame retardants. Environ. Sci. Technol. 2008, 42 (5), 1452-1457.

(20) Dickhut, R.M.; Cincinelli, A.; Cochran, M.A.; Ducklow, H.W. Atmospheric Concentrations and AirWater Flux of Organochlorine Pesticides along the Western Antarctic Peninsula. Environ. Sci. Technol. 2005, 39 (2), 465-470.

(21) Gambaro, A.; Manodori, L.; Zangrando, R.; Cincinelli, A.; Capodaglio, G.; Cescon, P. Atmospheric PCB Concentrations at Terra Nova Bay, Antarctica. Environ. Sci. Technol. 2005, 39 (24), 9406-9411.

(22) Xie, Z.; Möller, A.; Ahrens, L.; Sturm, R.; Ebinghaus, R. Brominated Flame Retardants in Seawater and Atmosphere of the Atlantic and the Southern Ocean. Environ. Sci. Technol. 2011, 45 (5), 1820-1826.

(23) Wang, X.-M.; Ding, X.; Mai, B.-X.; Xie, Z.-Q.; Xiang, C.-H.; Sun, L.-G.; Sheng, C.-Y.; Fu, J.-M.; Zeng, E.Y. Polybrominated diphenyl ethers in airborne particulates collected during a research expedition from the Bohai Sea to the arctic. Environ. Sci. Technol. 2005, 39 (20), 7803-7809.

(24) de Wit, C.A. An overview of brominated flame retardants in the environment. Chemosphere 2002, 46 (5), 583-624.

(25) Pakalin, S.; Cole, T.; Steinkellner, J.; Nicolas, R.; Tissier, C.; Munn, S.; Eisenreich, S. Review on production processes of decabromodiphenyl ether (decaBDE) used in polymeric applications in electrical and electronic equipment, and assessment of the availability of potential alternatives to decaBDE. European Chemicals Bureau, Institute of Health and Consumer Protection, Joint Research Centre, European Commission. 2007, EUR 22693 EN.

(26) Shouse, B. Fire guts British Antarctic lab. Science 2001, 294, (5540), 33.

(27) La Guardia, M.J.; Hale, R.C.; Harvey, E. Detailed polybrominated diphenyl ether (PBDE) congener composition of the widely used penta-, octa-, and deca-PBDE technical flame-retardant mixtures. Environ. Sci. Technol. 2006, 40 (20), 6247-6254.

(28) Eriksson, J.; Green, N.; Marsh, G.; Bergman, Å. Photochemical decomposition of 15 polybrominated diphenyl ether congeners in methanol/water. Environ. Sci. Technol. 2004, 38 (11), 3119-3125.

(29) Fang, L.; Huang, J.; Yu, G.; Wang, L. Photochemical degradation of six polybrominated diphenyl ether congeners under ultraviolet irradiation in hexane. Chemosphere 2008, 71 (2), 258-267.

(30) Harner, T.; Shoeib, M. Measurements of octanol-air partition coefficients $\left(K_{\mathrm{OA}}\right)$ for polybrominated diphenyl ethers (PBDEs): Predicting partitioning in the environment. J. Chem. Eng. Data 2002, 47 (2), 228-232.

(31) Mazzera, D. M.; Lowenthal, D. H.; Chow, J. C.; Watson, J. G.; Grubǐsíc, V. PM10 measurements at McMurdo Station, Antarctica. Atmos. Environ. 2001, 35 (10), 1891-1902.

(32) Franz, T.P.; Eisenreich, S.J. Snow scavenging of polychlorinated biphenyls and polycyclic aromatic hydrocarbons in Minnesota. Environ. Sci. Technol. 1998, 32 (12), 1771-1778.

(33) Clarke, A. D. Aerosol light absorption by soot in remote environments. Aerosol Sci. Technol. 1989, 10 (1), 161-171. 
(34) Warren, S. G.; Clarke, A. D. Soot in the atmosphere and snow surface of Antarctica. J. Geophys. Res. 1990, 95 (D2), 1811-1816.

(35) DIRECTIVE 2003/11/EC OF THE EUROPEAN PARLIAMENT AND OF THE COUNCIL of 6 February 2003 amending for the 24th time Council Directive 76/769/EEC relating to restrictions on the marketing and use of certain dangerous substances and preparations (pentabromodiphenyl ether, octabromodiphenylether). Off. J. Eur. Communities: Legislation 15.2.2003

(36) BSEF Legislative and Regulatory Activities Brominated Flame Retardants; Bromine Science and Environmental Forum, Washington, DC, April 2007;

www.dsbg.com/Brome/brome.nsf/3dfce89c50ffb6194225661d0061e2df/83a130e5e3eca245c22572c500 289dab/\$FILE/BFR_Leg_Update_4.19.07.pdf.

(37) Hung, H.; Kallenborn, R.; Breivik, K.; Su, Y. S.; Brorström-Lundén, E.; Olafsdottir, K.; Thorlacius, J. M.; Leppanen, S.; Bossi, R.; Skov, H.; Mano, S.; Patton, G. W.; Stern, G.; Sverko, E.; Fellin, P. Atmospheric monitoring of organic pollutants in the Arctic under the Arctic Monitoring and Assessment Programme (AMAP): 1993-2006. Sci. Tot. Environ. 2010, 408 (15), 2854-2873.

(38) Perovich, D.K.; Elder, B.C.; Claffey, K.J.; Stammerjohn, S.; Smith, R.; Ackley, S.F.; Krouse, H.R.; Gow, A.J. Winter sea-ice properties in Marguerite Bay, Antarctica. Deep-Sea Res. II 2004, $512023-$ 2039.

(39) Tittlemier, S.A.; Halldorson, T.; Stern, G.A.; Tomy, G.T. Vapor pressures, aqueous solubilities, and Henry's law constants of some brominated flame retardants. Environ. Toxicol. Chem. 2002, 21 (9), 1804-1810.

(40) Marshall, J.; Plumb, R.A. Atmosphere, Ocean, and Climate Dynamics An Introductory Text; Elsevier, Academic Press: London, UK, 2008.

(41) Warneck, P. Chemistry of the Natural Atmosphere; Academic Press: San Diego, CA, 1988.

(42) HYSPLIT (HYbrid Single-Particle Lagrangian Integrated Trajectory) Model access via NOAA ARL READY Website (http://ready.arl.noaa.gov/HYSPLIT.php). NOAA Air Resources Laboratory, Silver Spring, MD.

(43) Real-time Environmental Applications and Display sYstem (READY) Website (http://ready.arl.noaa.gov). NOAA Air Resources Laboratory, Silver Spring, MD. 